\title{
Analisa Association Rule Pada Algoritma Apriori Untuk Minat Pembelian Alat Kesehatan
}

\author{
Andi Rahmadsyah, Hartono, Rika Rosnelly \\ Fakultas Teknik dan Ilmu komputer, Prodi Magister Ilmu Komputer, Universitas Potensi Utama, Medan, Indonesia \\ Email: 1,"${ }^{*}$ andijohorr@gmail.com, ${ }^{2}$ hartonoibbi@gmail.com, ${ }^{3}$ rikarosnelly@gmail.com \\ Email Penulis Korespondensi: andijohorr@gmail.com
}

\begin{abstract}
Abstrak-Dalam persaingan di dunia bisnis, khususnya industri Alat Kesehatan, menuntut para pengembang untuk menemukan suatu strategi jitu yang dapat meningkatkan penjualan barang. Salah satu cara mengatasinya adalah dengan tetap tersediaannya berbagai jenis alat-alat kesehatan secara kontinu digudang. Untuk mengetahui alat-alat kesehatan apa saja yang dibeli oleh para konsumen, dilakukan teknik analisis keranjang pasar yaitu analisis dari kebiasaan membeli konsumen. Untuk mempermudah Perusahaan dalam menentukan minat pembeli terhadap alat kesehatan diperlukan suatu metode data mining yang disertai dengan algoritma apriori didasarkan pada proses pembelian yang dilakukan oleh konsumen berdasarkan keterkaitan antar produk yang dibeli. Berdasarkan sampel data penjualan Alat kesehatan CV Andira Karya Jaya yang berjumlah 25 transaksi dan Pada penelitian ini akan digunakan minimum support $=12 \%$ dan minimum confidence $=70 \%$. Pada tahap akhir, diperoleh hasil yaitu didapatkan alat-alat kesehatan yang diminati oleh pembeli pada CV. Andira Karya Jaya yaitu tabung oksigen 1 M3 dan troley oksigen $1 \mathrm{M} 3$. Beradasarkan data tersebut, pihak CV. Andira karya jaya dapat menyediakan persediaan alat-alat kesehatan yang diminati oleh pembeli.
\end{abstract}

Kata Kunci: Alat Kesehatan, Data Mining, Apriori.

\begin{abstract}
In the competition in the business world, especially the Medical Device industry, it requires developers to find an accurate strategy that can increase sales of goods. One way to overcome this problem is to continue to provide various types of medical devices in the warehouse. To find out what medical devices are purchased by consumers, market basket analysis techniques are carried out, namely analysis of consumer buying habits. In order to make it easier for companies to determine Buyers' interest in medical devices, a data mining method is needed which is accompanied by an a priori algorithm based on the purchasing process carried out by consumers based on the relationship between the products purchased. Based on the sample sales data for medical devices CV Andira Karya Jaya, amounting to 25 transactions and in this study a minimum support $=12 \%$ and a minimum confidence $=70 \%$ will be used. In the final stage, the results obtained are medical devices that are in demand by buyers at CV. Andira Karya Jaya, namely $1 \mathrm{M} 3$ oxygen cylinder and $1 \mathrm{M} 3$ troley of oxygen. Based on this data, CV. Andira Karya Jaya can provide supplies of medical devices that are of interest to buyers.
\end{abstract}

Keywords: Medical Devices; Data Mining; Apriori

\section{PENDAhUluan}

Pada dunia bisnis, informasi ialah data yang sangat berarti guna memperluas meningkatkan ruang bisnisnya. Buat mendapatkan perihal itu, terdapat sebagian metode yang wajib dicoba ialah tingkatkan mutu produk, mengoptimalkan tipe produk, serta mengurangi bayaran operasional industri. Seluruh metode tersebut bisa dicoba dengan satu langkah ialah analisis informasi industri.

CV Andira Karya Jaya adalah Perusahaan yang bergerak dibidang penjualan alat kesehatan. Alat kesehatan merupakan salah satu bagian penting dalam pelayanan kesehatan yang digunakan untuk membantu dalam pencegahan, penegakkan diagnosa, pengobatan maupun pemulihan penyakit. Dalam persaingan di dunia bisnis, khususnya industri Alat Kesehatan, menuntut para pengembang untuk menemukan suatu strategi jitu yang dapat meningkatkan penjualan barang. Salah satu cara mengatasinya adalah dengan tetap tersediaannya berbagai jenis alat-alat kesehatan secara kontinu digudang. Untuk mengetahui alat-alat kesehatan apa saja yang dibeli oleh para konsumen, dilakukan teknik analisis keranjang pasar yaitu analisis dari kebiasaan membeli konsumen. Untuk mempermudah Perusahaan dalam menentukan minat Pembeli terhadap alat kesehatan diperlukan suatu metode data mining. Data mining berfungsi untuk memberikan solusi kepada para pengambil keputusan dalam bisnis guna meningkatkan bisnis perusahaan [1][2][3][4][5]. Dalam proses data mining terdapat beberapa algoritma atau metode salah satunya yaitu algoritma Apriori yang termasuk dalam aturan asosiasi dalam data mining. Algoritma Apriori bertujuan untuk menemukan frequent item sets di sekumpulan data. Algoritma Apriori yaitu suatu proses untuk menemukan suatu aturan Apriori yang memenuhi syarat minimum untuk support dan syarat minimum untuk confidence.

Association rule( ketentuan asosiasi), ialah metode informasi mining buat menciptakan ketentuan asosiatif sesuatu campuran item. Pencarian pola asosiasi berawal dari pengolahan informasi transaksi penjualan perlengkapan kesehatan, setelah itu dicari ikatan antar perlengkapan kesehatan yang dibeli. Proses pencarian asosiasi ini memakai dorongan algoritma apriori yang ialah algoritma yang digunakan buat menciptakan association rule dengan pola" if then" yang berperan buat membentuk campuran item yang bisa jadi, setelah itu diuji apakah campuran tersebut penuhi parameter support serta confidence minimum yang ialah nilai ambang yang diberikan oleh user[6][7][8].

Penelitian terdahulu [9] dengan menggunakan algoritma apriori dapat diterapkan pada sistem simulasi prediksi hujan. Semakin tinggi minimum support dan minimum confidence yang digunakan maka semakin 
sedikit jumlah frequent itemset dan rule yang terbentuk serta akurasi semakin berkurang. Semua rule yang dihasilkan pada penelitian ini memiliki nilai lift ratio lebih dari 1.00 sehingga dapat digunakan sebagai acuan dalam memprediksi hujan.

Penelitian [10] ini sukses menganalisa informasi transaksi peminjaman buku buat mengenali buku- buku yang kerap dipinjam secara bertepatan memakai algoritma Apriori. Hasil dari analisa pada seluruh informasi transaksi peminjaman buku dari tahun 2016- 2018 bisa disimpulkan kalau bila peminjam meminjam buku dengan jenis buku agama hingga hendak meminjam bukul dengan jenis novel ilmu sosial ketentuan ini memilik nilai support $11,71 \%$ serta confidence $41,43 \%$ serta bila wisatawan meminjam buku dengan jenis buku teknologi hingga hendak meminjam buku dengan jenis buku ilmu sosial ketentuan ini mempunyai nilai support $13,8 \%$ serta confidence $40,75 \%$.

Penelitian ini [11] berhasil menganalisa data transaksi peminjaman buku untuk mengetahui buku-buku yang sering dipinjam secara bersamaan menggunakan algoritma Apriori. Dari data 11.550 transaksi peminjaman buku selama 3 tahun yang telah diproses menghasilkan 4 rules dengan kombinasi item terbesar adalah kategori buku agama dan ilmu sosial sering dipinjam secara bersamaan dengan nilai support $11,71 \%$ dan confidence $41,43 \%$. Selain itu, kategori buku teknologi dan ilmu sosial sering dipinjam secara bersamaan dengan nilai support $13,8 \%$ dan confidence $40,75 \%$.

Penelitian sebelumnya[12] Dengan menerapkan proses association rule menggunakan algoritma Apriori dapat membantu pihak manajemen untuk menganalsis proses penjualan dan pola keterhubungan antar spare part dan dapat diketahui produk yang paling banyak dibeli oleh konsumen. bagian penjualan dapat sesegera mungkin membuat laporan penjualan khusus terhadap spare part yang bersangkutan, untuk membuat pengajuan restock persediaan spare part sehingga kebutuhan terhadap spare part dapat selalu tersedia.

Pada penelitian ini, penulis akan melakukan analisis terhadap data transaksi penjualan alat kesehatan yang akan dilakukan dengan mekanisme perhitungan nilai support dan confident dari suatu hubungan item, yang nantinya hasil nilai support dan confident akan menghasilkan pola minat pembeli alat kesehatan dan akan digunakan untuk proses pengambilan keputusan oleh pihak CV Andira Karya Jaya untuk meningkatkan strategi pemasaran.

\section{METODOLOGI PENELITIAN}

\subsection{Kerangka Kerja Penelitian}

Kerangka kerja riset terbuat secara sistematis yang menuju pada tahapan proses yang hendak ditempuh pada riset ini bisa dilihat pada gambar 1 .

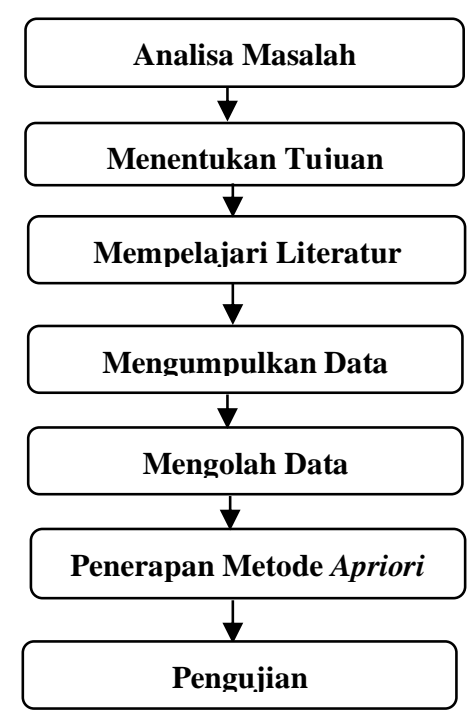

1. Analisis Masalah

Gambar 1. Kerangka Penelitian

Menganalisa masalah adalah langkah awal dalam penelitian, dengan memahami identifikasi masalah dan batasan masalah, diharapkan peneliti dapat memahami masalah menentukan minat pembeli alat-alat kesehatan dengan baik.

\section{Menentuan Tujuan}

Menentukan tujuan penelitian, akan menentukan target dan solusi dalam mengatasi masalah pada minat beli alatalat kesehatan.

\section{Mempelajari Literatur}


JURNAL MEDIA INFORMATIKA BUDIDARMA

Volume 5, Nomor 1, Januari 2021, Page 280-286

ISSN 2614-5278 (media cetak), ISSN 2548-8368 (media online)

Available Online at https://ejurnal.stmik-budidarma.ac.id/index.php/mib

DOI 10.30865/mib.v5i1.2658

Peneliti mempelajari literatur yang berhubungan dengan penelitian, adapun yang digunakan dalam literatur yaitu buku-buku, jurnal, artikel dan bahan bacaan lainnya.

\section{Mengumpulan Data}

Dalam Pengumpulan data, peneliti melakukan observasi langsung di CV. Andira Karya Jaya. Data yang digunakan adalah laporan penjualan alat-alat kesehatan.

\section{Mengolah Data}

Tahap selanjutnya mengolah data yang telah dikumpulkan. Data awal laporan penjualan alat-alat kesehatan diloah berdasarkan tahapan pada algoritma yang digunakan oleh peneliti.

\section{Penerapan Metode Apriori}

Menerapkan metode dimana dilakukan perhitungan manual berdasarkan data awal sesuai dengan algoritma Apriori.

\section{Pengujian}

Pada Tahapan ini, dilakukan pengujian antara perhitungan manual dengan perhitungan dengan menggunakan tools.

\subsection{Tahapan Association Rule}

Analisis asosiasi dikenal juga sebagai salah satu teknik data mining yang menjadi dasar dari berbagai teknik data mining lainya. Khususnya salah satu tahap dari analisis asosiasi yang disebut analisis pola frekuensi tinggi (frequent pattern mining) menarik perhatian banyak peneliti untuk menghasilkan algoritma yang efesisien.

Metodologi dasar analisis asosiasi terbagi menjadi dua tahap [8][13] :

1. Analisa pola frekuensi tinggi

Tahap ini mencari kombinasi item yang memenuhi syarat minimum dari support dalam database. Nilai support sebuah item diperoleh dengan memakai rumus berikut :

$$
\text { Support }(\mathrm{A})=\frac{\text { JumlahTransaksi Mengandung A }}{\text { Total Transaksi }}
$$

Sedangkan nilai dari support dua item diperoleh dari rumus berikut :

$$
\operatorname{Support}(\mathrm{A}, \mathrm{B})=(\mathrm{A} \Omega \mathrm{B})
$$

$$
\underline{\text { Jumlah Transaksi Mengandung A dan B }}
$$

$$
\text { Total Transaksi }
$$

2. Pembentukan Aturan Asosiasi Setelah semua pola frekuensi tinggi ditemukan, barulah dicari aturan assosiatif yang memenuhi syarat minimum untuk confidence dengan menghitung confidence aturan asosiasi " jika A maka B ". Nilai confidence dari aturan " jika A maka B " diperoleh dari rumus berikut : Confidence = $\mathrm{P}(\mathrm{B} \mid \mathrm{A})=$

$$
\frac{\text { Jumlah Transaksi Mengandung A dan B }}{\text { Jumlah Trasnsaksi Mengandung A }}
$$

\subsection{Algoritma Apriori}

Algoritma apriori memakai pengetahuan mengenai frequent itemset yang telah diketahui sebelumnya, untuk memproses informasi selanjutnya. Pola frekuensi besar merupakan pola- pola item dalam database yang mempunyai frekuensi ataupun support di atas ambang batasan tertentu yang diucap sebutan minimum support. Pola frekuensi besar ini digunakan buat menyusun ketentuan asosiatif serta pula sebagian metode informasi mining yang lain. Prinsip dari algoritma apriori adalah[14][15][16] :

1. Kumpulkan jumlah item tunggal, dapatkan item besar

2. Dapatkan candidate pairs, hitung $\rightarrow$ large pairs dari item-item

3. Dapatkan candidate triplets, hitung $\rightarrow$ large triplets dari item-item dan seterusnya

4. Sebagai petunjuk : setiap subset dari sebuah frequent itemset harus menjadi frequent.

\subsection{Alat Kesehatan}

Berdasarkan PERMENKES 1189-1190-1191 tahun 2010 menjelaskan alat kesehatan adalah instrumen, apparatus, mesin dan atau implan yang tidak mengandung obat yang digunakan untuk mencegah, mendiagnosis, menyembuhkan dan meringankan penyakit, merawat orang sakit, memulihkan kesehatan pada manusia, dan atau membentuk struktur dan memperbaiki fungsi tubuh. Contoh spiut, alcohol swab, dan lain sebagainya [17]

\section{HASIL DAN PEMBAHASAN}

\subsection{Pengolahan Data}

Dilakukan pengumpulan data, yaitu berupa data penjualan alat kesehatan di CV Andira Karya Jaya, data alat-alat kesehatan keluar terdiri atas tanggal, kode jual, nama barang. 
JURNAL MEDIA INFORMATIKA BUDIDARMA

Volume 5, Nomor 1, Januari 2021, Page 280-286

ISSN 2614-5278 (media cetak), ISSN 2548-8368 (media online)

Available Online at https://ejurnal.stmik-budidarma.ac.id/index.php/mib

DOI 10.30865/mib.v5i1.2658

Tabel 1. Daftar Penjualan Alat Kesehatan

\begin{tabular}{|c|c|c|c|}
\hline No & Tanggal & Kode Jual & Nama Barang \\
\hline \multirow[t]{4}{*}{1} & $02-$ Oct-2020 & JL. 0020865 & SENTER KEPALA S-1 \\
\hline & & & TABUNG OKSIGEN 1M3 \\
\hline & & & TROLEY OKSIGEN 1M3 D \\
\hline & & & ICE BAG ONEMED \\
\hline \multirow[t]{4}{*}{2} & 06-Oct-2020 & JL. 0021172 & BOLA TERAPI BERDURI KARET \\
\hline & & & TABUNG OKSIGEN 1M3 \\
\hline & & & TROLEY OKSIGEN 1M3 D \\
\hline & & & ICE BAG ONEMED \\
\hline \multirow[t]{2}{*}{3} & 07-Oct-2020 & JL. 0021224 & TENSIMETER DIGITAL OMRON 8712 \\
\hline & & & THERMOMETER DIGITAL OMRON \\
\hline \multirow{3}{*}{4} & 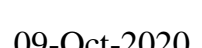 & II 0007085 & PINSET ANATOMI 14 CM \\
\hline & $09-0 \mathrm{ct}-2020$ & JL. 000/085 & GAGANG PISAU NO.3 \\
\hline & & & ARTERI KLEM LURUS 12 CM \\
\hline \multirow{3}{*}{5} & & & ARTERI KLEM LURUS 14 CM \\
\hline & 09-Oct-2020 & JL. $000 / 086$ & ARTERI KLEM BENGKOK 14 CM \\
\hline & & & TIMBANGAN GEA TEBAL \\
\hline \multirow{3}{*}{6} & & & GUNTING TAJAM TUMPUL LURUS \\
\hline & 09-Oct-2020 & JL. 0007087 & NEEDLE HOLDER 14 CM \\
\hline & & & TAS P3K SELEMPANG \\
\hline \multirow{3}{*}{7} & & II 0007158 & MASKER SENSI \\
\hline & 09-Oct-2020 & JL. $000 / 158$ & ASEPTIC GEL ANIOS 500 ML \\
\hline & & & PELINDUNG MUKA HELM \\
\hline \multirow{3}{*}{8} & & UI 0021455 & STETOSKOP GEA EKONOMI \\
\hline & 09-Oct-2020 & JL. 0021453 & TENSIMETER ANEROID GENERAL CARE \\
\hline & & & DOPLER HI BEBE LCD \\
\hline 9 & 10-Oct-2020 & JL. 0021598 & DOPLER HI BEBE LCD \\
\hline-- & ------- & ----------------- & ----------------------------------------------------------- \\
\hline 23 & 27-Sept-2020 & JL. 0011413 & $\begin{array}{l}\text { ALAT BANTU DENGAR COFOE } \\
\text { KACAMATA GOGGLE KARET }\end{array}$ \\
\hline \multirow[t]{2}{*}{24} & & JL. 0020510 & REGULATOR O2 GEA \\
\hline & 28-Sept-2020 & & $\begin{array}{l}\text { TABUNG OKSIGEN 1M3 } \\
\text { TROLEY OKSIGEN 1M3 D }\end{array}$ \\
\hline \multirow{3}{*}{25} & & & ALAT TINDIK TELINGA \\
\hline & & II 0016040 & TIMBANGAN DIGITAL BAYI OD \\
\hline & 29-Sept-2020 & JL. 0010040 & SARUNG TANGAN MACAN M \\
\hline
\end{tabular}

Sesi dalam menganalisa informasi dengan algoritma Apriori pada penjualan diawali dengan menyeleksi serta mensterilkan informasi informasi yang hendak dianalisis, setelah itu mencari seluruh tipe item nama alatalat kesehatan yang terdapat didalam list transaksi penjualan, selanjutnya mencari jumlah tiap item yang terdapat pada tiap transaksi penjualan( alat-alat kesehatan).

\subsection{Penerapan Algoritma Apriori}

\subsubsection{Analisa Pola Frekuensi Tinggi}

Tahapan ini mencari kombinasi item yang memenuhi syarat minimum dari nilai support dalam database. Nilai support sebuah item diperoleh dengan rumus berikut :

$$
\operatorname{Support}(\mathrm{A})=\frac{\text { JumlahTransaksi Mengandung A }}{\text { Total Transaksi }}
$$

Sedangkan nilai support dari 2 item diperoleh dengan rumus berikut:

$\operatorname{Support}(\mathrm{A}, \mathrm{B})=(\mathrm{A} \Omega \mathrm{B})$

Jumlah Transaksi Mengandung A dan B

Total Transaks

Tabel 2. Daftar Jenis items Alat-alat Kesehatan

\begin{tabular}{|c|c|c|c|}
\hline No & Nama Item & Support & $\begin{array}{c}\text { Support } \\
(\%)\end{array}$ \\
\hline
\end{tabular}


JURNAL MEDIA INFORMATIKA BUDIDARMA

Volume 5, Nomor 1, Januari 2021, Page 280-286

ISSN 2614-5278 (media cetak), ISSN 2548-8368 (media online)

Available Online at https://ejurnal.stmik-budidarma.ac.id/index.php/mib DOI 10.30865/mib.v5i1.2658

\begin{tabular}{|c|c|c|c|}
\hline No & Nama Item & Support & $\begin{array}{c}\text { Support } \\
(\%)\end{array}$ \\
\hline 1 & ALAT BANTU DENGAR COFOE & 1 & $4 \%$ \\
\hline 2 & ALAT TINDIK TELINGA & 1 & $4 \%$ \\
\hline 3 & ARTERI KLEM BENGKOK 14 CM & 1 & $4 \%$ \\
\hline 4 & ARTERI KLEM LURUS 12 CM & 1 & $4 \%$ \\
\hline 5 & ARTERI KLEM LURUS 14 CM & 1 & $4 \%$ \\
\hline 6 & ASEPTIC GEL ANIOS 500 ML & 1 & $4 \%$ \\
\hline 7 & ASEPTIC GEL ONEMED 500 ML & 1 & $4 \%$ \\
\hline 8 & BAJU OK BIRU MUDA PANJANG M & 1 & $4 \%$ \\
\hline 9 & BAJU OK MERAH MARON PANJANG XL & 1 & $4 \%$ \\
\hline 10 & BAJU OK NAVY PANJANG L & 1 & $4 \%$ \\
\hline 11 & BAJU OK NAVY PANJANG M & 1 & $4 \%$ \\
\hline 12 & BOLA TERAPI BERDURI KARET & 2 & $8 \%$ \\
\hline 13 & CELEMEK WARNA APRON & 2 & $8 \%$ \\
\hline 14 & DOPLER HI BEBE LCD & 2 & $8 \%$ \\
\hline 15 & GAGANG PISAU NO.3 & 1 & $4 \%$ \\
\hline 16 & GUNTING TAJAM TUMPUL LURUS & 1 & $4 \%$ \\
\hline 17 & ICE BAG ONEMED & 2 & $8 \%$ \\
\hline 18 & KACAMATA GOGGLE KARET & 3 & $12 \%$ \\
\hline 19 & KURSI RODA 3 FUNGSI 609 GCU GEA & 1 & $4 \%$ \\
\hline 20 & KURSI RODA JARI GEA FS 871 & 1 & $4 \%$ \\
\hline 21 & MASKER SENSI & 1 & $4 \%$ \\
\hline 22 & NEEDLE HOLDER 14 CM & 1 & $4 \%$ \\
\hline 23 & P3K DOMPET & 1 & $4 \%$ \\
\hline 24 & PELINDUNG MUKA & 1 & $4 \%$ \\
\hline 25 & PELINDUNG MUKA 7 & 2 & $8 \%$ \\
\hline 26 & PELINDUNG MUKA ANAK & 1 & $4 \%$ \\
\hline 27 & PELINDUNG MUKA HELM & 1 & $4 \%$ \\
\hline 28 & PELINDUNG MUKA KACAMATA & 1 & $4 \%$ \\
\hline 29 & PINSET ANATOMI 14 CM & 1 & $4 \%$ \\
\hline 30 & PIPET TETES PENDEK KUNING 9CM & 1 & $4 \%$ \\
\hline 31 & REGULATOR O2 GEA & 1 & $4 \%$ \\
\hline 32 & REGULATOR O2 NESCO & 1 & $4 \%$ \\
\hline 33 & SARUNG TANGAN MACAN M & 2 & $8 \%$ \\
\hline 34 & SENTER KEPALA S-1 & 1 & $4 \%$ \\
\hline 35 & STANDARD INFUS PUTIH & 2 & $8 \%$ \\
\hline 36 & STETOSKOP GEA EKONOMI & 1 & $4 \%$ \\
\hline 37 & STETOSKOP GENERAL CARE PREMIUM & 2 & $8 \%$ \\
\hline 38 & TABUNG OKSIGEN 1M3 & 3 & $12 \%$ \\
\hline 39 & TABUNG OKSIGEN 1M3 BARU & 2 & $8 \%$ \\
\hline 40 & TAS P3K SELEMPANG & 2 & $8 \%$ \\
\hline 41 & TEMPAT GANTUNGAN ASEPTIC PLASTIK & 1 & $4 \%$ \\
\hline 42 & TENSIMETER ANEROID GEA MD & 2 & $8 \%$ \\
\hline 43 & TENSIMETER ANEROID GENERAL CARE & 4 & $16 \%$ \\
\hline 44 & TENSIMETER ANEROID ONEMED & 1 & $4 \%$ \\
\hline 45 & TENSIMETER ANEROID ONEMED P & 1 & $4 \%$ \\
\hline 46 & TENSIMETER DIGITAL DR CARE HL 168 & 1 & $4 \%$ \\
\hline 47 & TENSIMETER DIGITAL OMRON 8712 & 1 & $4 \%$ \\
\hline 48 & THERMOMETER DIGITAL OMRON & 1 & $4 \%$ \\
\hline 49 & TIMBANGAN DIGITAL BAYI OD & 1 & $4 \%$ \\
\hline 50 & TIMBANGAN GEA TEBAL & 1 & $4 \%$ \\
\hline 51 & TROLEY INSTRUMEN 3 TINGKAT & 1 & $4 \%$ \\
\hline 52 & TROLEY OKSIGEN 1M3 & 1 & $4 \%$ \\
\hline 53 & TROLEY OKSIGEN 1M3 D & 4 & $16 \%$ \\
\hline
\end{tabular}

Berdasarkan data telah terbentuk data 1 item dari alat-alat kesehatan, Sedangkan Tabel 3 adalah item data yang terpilih dengan minimal support adalah $12 \%$. Seperti yang terlihat pada tabel berikut ini: 
Tabel 3. Daftar Jenis items Alat-alat Kesehatan dengan support yang telah ditentukan

\begin{tabular}{clcc}
\hline No & \multicolumn{1}{c}{ Nama Item } & Support & Support (\%) \\
\hline $\mathbf{1}$ & KACAMATA GOGGLE KARET & 3 & $12 \%$ \\
$\mathbf{2}$ & TABUNG OKSIGEN 1M3 & 3 & $12 \%$ \\
$\mathbf{3}$ & TENSIMETER ANEROID GENERAL CARE & 4 & $16 \%$ \\
$\mathbf{4}$ & TROLEY OKSIGEN 1M3 D & 4 & $16 \%$ \\
\hline
\end{tabular}

\subsubsection{Pembentukan Pola Kombinasi dua items}

Pembuatan pola frekuensi 2 item, dibentuk dari items jenis perlengkapan kesehatan yang memenuhi support minimal yakni dengan tata cara mengkombinasi segala items kedalam 2 kombinasi, hasil dari kombinasi 2 items semacam pada tabel 4 berikut ini:

Tabel 4. Daftar Calon Pola Kombinasi Dua itemset

\begin{tabular}{clcc}
\hline No & \multicolumn{1}{c}{ Nama Item } & Support & $\begin{array}{c}\text { Support } \\
(\boldsymbol{\%})\end{array}$ \\
\hline $\mathbf{1}$ & KACAMATA GOGGLE KARET, TABUNG OKSIGEN 1M3 & 0 & 0 \\
$\mathbf{2}$ & KACAMATA GOGGLE KARET, TENSIMETER ANEROID & 1 & $4 \%$ \\
& GENERAL CARE & 0 & 0 \\
$\mathbf{3}$ & KACAMATA GOGGLE KARET, TROLEY OKSIGEN 1M3 D & 0 & 0 \\
$\mathbf{4}$ & TABUNG OKSIGEN 1M3, TENSIMETER ANEROID GENERAL & & $12 \%$ \\
$\mathbf{5}$ & CARE & 3 & 0 \\
$\mathbf{6}$ & TABUNG OKSIGEN 1M3, TROLEY OKSIGEN 1M3 D & 0 & 0 \\
\hline
\end{tabular}

Tabel 5. Daftar Pola kombinasi dua items yang memenuhi support minimal

\begin{tabular}{clcc}
\hline No & \multicolumn{1}{c}{ Nama Item } & $\begin{array}{c}\text { Support } \\
\text { Support } \\
(\mathbf{\%})\end{array}$ \\
\hline $\mathbf{1}$ & KACAMATA GOGGLE KARET, TABUNG OKSIGEN 1M3 & 0 & 0 \\
$\mathbf{2}$ & KACAMATA GOGGLE KARET, TENSIMETER ANEROID & 1 & $4 \%$ \\
& GENERAL CARE & 0 & 0 \\
$\mathbf{3}$ & KACAMATA GOGGLE KARET, TROLEY OKSIGEN 1M3 D & 0 & 0 \\
$\mathbf{4}$ & TABUNG OKSIGEN 1M3, TENSIMETER ANEROID GENERAL & 0 & $12 \%$ \\
& CARE & 3 & 0 \\
$\mathbf{5}$ & TABUNG OKSIGEN 1M3, TROLEY OKSIGEN 1M3 D & 0 & 0 \\
$\mathbf{6}$ & TENSIMETER ANEROID GENERAL CARE, TROLEY OKSIGEN & & \\
& 1M3 D & & \\
\hline
\end{tabular}

\subsubsection{Pembentukan Pola Aturan Asosiasi}

Pembuatan association rule merupakan menganalisis pola frekuensi besar, sesi ini mencari campuran yang penuhi ketentuan minimum dari support dalam database, Pembuatan aturan association rule, dengan mencari nilai confidence. Dimana support merupakan jumlah dari campuran antara sesuatu item dengan item yang lain sedangankan confidence merupakan nilai yang mendefinisikan kuat tidaknya ikatan antara item- item tersebut.

Confidence $=\mathrm{P}(\mathrm{B} \mid \mathrm{A})=\frac{\text { Jumlah Transaksi Mengandung A dan } \mathrm{B}}{\text { Jumlah Transaksi Mengandung } \mathrm{A}}$

Dari tabel 5 yaitu tabel pola kombinasi dua item, dengan menetapkan nilai confidence minimum adalah 70 persen $(\%)$, maka aturan yang bisa terbentuk adalah aturan seperti pada tabel 6 .

Tabel 6. Daftar Calon Aturan Asosiasi

\begin{tabular}{cllc}
\hline No & Kombinasi Item & \multicolumn{2}{c}{ Confidence } \\
\hline $\mathbf{1}$ & $\begin{array}{l}\text { Jika membeli TABUNG OKSIGEN 1M3 maka } \\
\text { membeli TROLEY OKSIGEN 1M3 D }\end{array}$ & $3 / 3$ & $100 \%$ \\
$\mathbf{2}$ & $\begin{array}{l}\text { Jika membeli TROLEY OKSIGEN 1M3 D maka } \\
\text { membeli TABUNG OKSIGEN 1M3 }\end{array}$ & $3 / 4$ & $75 \%$ \\
\hline
\end{tabular}




\section{KESIMPULAN}

Dengan menganalisa Association Rule pada teknik data mining didapatkan alat-alat kesehatan yang diminati oleh pembeli pada CV. Andira Karya Jaya yaitu tabung oksigen 1 M3 dan troley oksigen 1 M3. Dengan nilai confidence minimum adalah 70\% maka terbentuklah aturan asosiasi : Jika membeli tabung oksigen $1 \mathrm{M} 3$ maka membeli troley oksigen 1 M3 D, Jika membeli TROLEY OKSIGEN 1M3 D maka membeli TABUNG OKSIGEN $1 \mathrm{M} 3$. Beradasarkan data tersebut, pihak CV. Andira karya jaya dapat menyediakan persediaan alat-alat kesehatan yang diminati oleh pembeli.

\section{REFERENCES}

[1] F. Harahap, "Penerapan data Mining dalam Pemilihan Mobil Menggunakan Algoritma C4.5," J. VOI (Voice Informatics), vol. 7, no. x, 2018.

[2] Hartono, "Model Optimisasi Hybrid Ensembles Dalam Menyelesaikan Permasalahan CLASS IMBALANCE," TECHSI-Jurnal Tek. Inform., pp. 54-67, 2019.

[3] S. Aliyah and F. Harahap, "Description Method to Find Patterns on Employee Attendance," 2020 8th Int. Conf. Cyber IT Serv. Manag. (CITSM), Pangkal Pinang, Indones., no. 1, pp. 21-24, 2020.

[4] M. Sadikin, R. Rosnelly, and T. S. Gunawan, "Perbandingan Tingkat Akurasi Klasifikasi Penerimaan Dosen Tetap Menggunakan Metode Naive Bayes Classifier dan C4 . 5," J. MEDIA Inform. BUDIDARMA, vol. 4, pp. 1100-1109, 2020, doi: $10.30865 /$ mib.v4i4.2434.

[5] F. Harahap, A. Y. N. Harahap, E. Ekadiansyah, R. N. Sari, R. Adawiyah, and C. B. Harahap, "Implementation of Naïve Bayes Classification Method for Predicting Purchase," 2018 6th Int. Conf. Cyber IT Serv. Manag. CITSM 2018, no. Citsm, pp. 1-5, 2019, doi: 10.1109/CITSM.2018.8674324.

[6] N. A. Hasibuan et al., "IMPLEMENTASI DATA MINING UNTUK PENGATURAN LAYOUT MINIMARKET DENGAN MENERAPKAN ASSOCIATION RULE,” vol. 4, no. 4, pp. 6-11, 2017.

[7] A. Fauzi, iis joice Marpaung, and A. M. H. Pardede, "Sistem Pendukung Pemilihan Pekerjaan Menggunakan Metode Apriori Berdasarkan Korelasi Jurusan Dengan Ipk Untuk Mengetahui Pekerjaan Yang Tepat," eminar Nas. "Inovasi dalam Desain dan Teknol. - IDeaTech 2015, vol. 2, no. 2, pp. 152-159, 2018.

[8] D. Listriani, A. H. Setyaningrum, and F. Eka, "PENERAPAN METODE ASOSIASI MENGGUNAKAN ALGORITMA APRIORI PADA APLIKASI ANALISA POLA BELANJA KONSUMEN (Studi Kasus Toko Buku Gramedia Bintaro),” J. Tek. Inform., vol. 9, no. 2, pp. 120-127, 2018, doi: 10.15408/jti.v9i2.5602.

[9] M. Fauzy, K. R. Saleh W, and I. Asror, "Penerapan Metode Association Rule Menggunakan Algoritma Apriori pada Simulasi Prediksi Hujan Wilayah Kota Bandung,” J. Ilm. Teknol. Inf. Terap., vol. II, no. 2, pp. 221-227, 2016, doi: 2407-3911

[10] R. M. Afdal M, "Penerapan Association Rule Mining Untuk Analisis Penempatan Tata Letak Buku Di Perpustakaan Menggunakan Algoritma Apriori," J. Ilm. Rekayasa dan Manag. Sist. Inf., vol. 5, no. 1, pp. 99-108, 2019.

[11] M. A. M. Afdal and M. Rosadi, "Penerapan Association Rule Mining Untuk Analisis Penempatan Tata Letak Buku Di Perpustakaan Menggunakan Algoritma Apriori," J. Ilm. Rekayasa dan Manaj. Sist. Inf., vol. 5, no. 1, p. 99, 2019, doi: 10.24014/rmsi.v5i1.7379.

[12] U. Ependi and A. Putra, "Solusi Prediksi Persediaan Barang dengan Menggunakan Algoritma Apriori (Studi Kasus: Regional Part Depo Auto 2000 Palembang)," J. Edukasi dan Penelit. Inform., vol. 5, no. 2, p. 139, 2019, doi: 10.26418/jp.v5i2.32648.

[13] M. Badrul, "Algoritma Asosiasi Dengan Algoritma Apriori Untuk Analisa Data Penjualan," J. Pilar Nusa Mandiri Vol.XII, vol. 12, no. 2, pp. 121-129, 2016.

[14] A. Anas, "Analisa Algorithma Apriori Untuk Mendapatkan Pola Peminjaman Buku Perpustakaan Smpn 3 Batanghari," J. Ilm. Media SISFO, vol. 10, no. 2, pp. 628-641, 2016.

[15] A. A. NUGROHO, "Membangun Aplikasi E-Commerce Dengan Sistem Penunjang Keputusan Metode Apriori Untuk Memberikan Rekomendasi Kepada Calon Pembeli Di Toko Islam Malang,” Inf. Technol., vol. 06, p. 11, 2018.

[16] R. Buaton, Y. Maulita, and A. R. Febria, "KORELASI KECERDASAN EMOSIONAL DENGAN PRESTASI BELAJAR SISWA MENGGUNAKAN METODE A PRIORI (STUDI KASUS: SMPIT ALKAFFAH BINJAI)," JIK (Jurnal Inform. Kaputama), vol. 1, no. 1, pp. 33-43, 2017.

[17] E. N. Salamah and N. Ulinnnuha, "Analisis Pola Pembelian Obat dan Alat Kesehatan di Klinik Ibu dan Anak Graha Amani dengan Menggunakan Algoritma Apriori,” J. Inf., vol. 2, no. 2, pp. 1-6, 2017, doi: 10.25139/ojsinf.v2i1.401. 